Aquaculture Economics \& Management

December 2006 ; Volume 10, Issue 3 : Pages 163 - 181

http://dx.doi.org/10.1080/13657300600985173

(C) 2006 Taylor \& Francis
Archimer http://www.ifremer.fr/docelec/ Archive Institutionnelle de l'Ifremer

The original publication is available at http://www.tandf.co.uk/journals/

\title{
Externalities, institutions and the location choices of shellfish producers: the case of blue mussel farming in the Mont-Saint-Michel Bay (France)
}

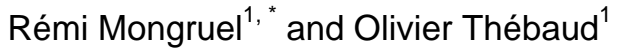 \\ ${ }^{1}$ Département d'Economie Maritime, Marine Economics Department, IFREMER Centre de Brest, Plouzané, \\ France \\ *: Corresponding author : R. Mongruel, email address : $\underline{\text { Remi.Mongruel@ifremer.fr }}$
}

\begin{abstract}
:
Most marine aquaculture activities remain strongly dependent on coastal ecosystems. In the case of shellfish farming, this dependency is related mainly to water quality and to the various ecological interactions resulting from the dynamics of coastal food webs. Such ecological constraints have influenced the overall evolution of blue mussel farming in the Mont-Saint-Michel Bay, leading producers to negotiate collective arrangements regarding production capacity and techniques and to develop production strategies at the farm level. This article presents an analysis of the location choices of mussel farmers in the Mont-Saint-Michel Bay based on an empirical investigation conducted in 2002. A typology of farms with respect to their land structure is developed in which some farms choose to concentrate their activity in a single part of the bay while others distribute their activity more widely. Determinants of the location choices of each farm category, including distance to port, natural productivity differentials, and predation of mussel stocks, are analyzed. The role of the institutional arrangements allowing mussel farmers to develop these location strategies is also discussed.
\end{abstract}

Keywords: blue mussel farming; economic performance indicators; externalities; location choices; institutional arrangements 


\section{Introduction}

There has been a tendency to consider aquaculture as an economic activity with a high degree of control over most if not all the stages of the production process, particularly when it is compared to capture fisheries. The fact that this activity usually develops in well delimited areas allocated to individual producers seems to play an important role in this perception. However, most marine aquaculture activities are strongly dependent on the coastal ecosystems in which they develop (Bailly \& Paquotte 1996, Asche et al. 1999, Muir et al. 1999, Nickerson 1999, Tisdell 1999, Berg 2002). The nature of this dependency will vary according to the species that is being farmed. Shellfish farming is both dependent on coastal water quality and an integral part of the trophic interactions which structure coastal food webs.

Since shellfish are filter feeders, the growth of a farmed stock of shellfish will depend strongly on the primary production of the waters in which they are grown. The quantity of primary production available to any given production area depends on (1) the local hydro-climatic conditions, (2) the "upstream" inputs in nutrients; and (3) the degree to which the resulting flow of primary production is used up by the other farmed and wild components of the coastal ecosystem (Fontenelle et al. 1998, Nickerson 1999, Goulletquer \& Le Moine 2002). Strong interactions may exist between a stock of farmed shellfish and the surrounding shellfish stocks. Individual farmers may have some control over access to production areas, especially where regulated as an individual allocation regime. However, the primary production of the coastal waters in which they operate can be considered as a common pool resource. This combination can lead to reciprocal negative externalities.

A second ecological constraint derives from the fact that shellfish constitute prey for a number of coastal species, particularly birds. Predation of the stocks has been recognized to have a significant impact on coastal shellfish exploitation (Wind \& de Kok 2002, PérezAgúndez \& Kalaydjian 2003, Howlett \& Rayner 2004). When predator species live in protected areas close to shellfish farming zones, this category of interaction can also be perceived by producers as a negative externality resulting from nature conservation policies. Location choices for shellfish farming serve as a key adaptation mechanism in response to these ecological constraints. Because primary production is not distributed homogeneously in coastal areas, individual producers will seek to locate their activity where this primary production is highest (Bailly 1994, Fontenelle et al. 1998, Fontenelle 2000, Mongruel 2002). Adaptation to predator-prey interactions can be twofold: (1) producers can try to reduce predation costs via the use of technical measures limiting predation; and (2) since the predation problem is usually not distributed homogeneously in space, producers can try to locate their activity where such predation is minimal.

Because these location choices are intimately related to the rules governing access to coastal areas for aquaculture development, it is important to take into account the nature of these rules in the analysis of location strategies. Indeed, such institutional dimensions have been shown to play a key role in the overall dynamics of aquaculture production in the coastal zone (Guillotreau \& Cunningham 1994, Aarset 1998, Primavera 2000, Marshall 2001, Hishamunda \& Ridler 2003, Howlett \& Rayner 2004).

This article presents an empirical analysis of the location choices of shellfish producers in response to ecological constraints in the case of blue mussel (Mytilus edulis) farming in the Mont-Saint-Michel Bay (France). The article begins with descriptions of mussel farming in the bay, of the ecological constraints on mussel farming, and the institutional context in which farms operate. This is followed by the materials and methods used in the empirical investigation of farming location choices, results, and discussion. 


\section{Ecological constraints and the development of blue mussel farming in the Mont-Saint-Michel Bay}

The Mont-Saint-Michel Bay is both a unique natural area and an ecosystem subject to various anthropogenic perturbations. Because it supports a wide range of human activities, the site is subject to many regulatory measures, including wild species conservation policies. Mussel farming activities thus interact not only with the ecosystem, but also with other human activities and the institutional framework (see Fontenelle et al. 1998, Fontenelle 2000, Lefeuvre et al 2000, Mongruel 2002). The following description focuses on how ecological constraints have influenced the overall evolution of blue mussel farming in the Mont-SaintMichel Bay, leading producers to negotiate collective arrangements regarding production capacity and techniques, and to develop production strategies at the farm level.

The annual production of mussels in the bay is estimated at approximately 10,000 tons, representing $15 \%$ of the French production of mussels by volume and $25 \%$ of mussels grown on mussel beds in France (Davaine 2002). The activity is carried out using wooden stakes (referred to as "bouchots") lined close to the shore in the tidal area. Blue mussel farming has developed relatively recently in the Mont-Saint-Michel Bay, in an area enclosed by oysterfarming zones to the West and North, and by a formerly contaminated zone to the East (Figure 1). The development pattern of blue mussel farming has been strongly related to the distribution of primary production in the bay. Mussel farming started in 1954, with the creation of two small production zones located on both sides of the small coastal river of Le Viviersur-mer (Figure 1). The initial expansion was extremely rapid, as evidenced by the evolution of the length of mussel bed lines, which rose from 12 kilometers in 1954, to 78 kilometers in 1958 and 128 kilometers in 1960. Spat from the South-West of France was introduced in 1957. Despite several interruptions in production due to the Mytilicola intestinalis parasite in the 1960s, the length of mussel bed lines increased to 197 kilometers in 1968 (Figure 2). This early development occurred in two zones: Cherrueix from 1958, and Saint-Benoît-desOndes from 1963 (Gasquet 1996, Le Mao \& Gerla 1998).

Differences in the biological productivity of farming zones soon became apparent, with a decreasing East/West gradient of productivity. This observation led to the transfer of some of the least productive lines of Saint-Benoît-des-Ondes to a new production zone located towards the East, North of the Banc des Hermelles (Figure 1), in 1975. A second partial transfer of existing mussel bed lines to this new zone took place during the 1980s. In 1983, the Hermelles zone was enlarged, and a third transfer took place in 1984, from the East of the Cherrueix zone to the West of the Hermelles zone (Gasquet 1996, Le Mao \& Gerla 1998, Fontenelle 2000, Verger \& Le Vot 2002). These transfers allowed significant productivity gains, which were soon weakened by new occurrences of Mytilicola intestinalis in 1983 and 1984 (Figure 2). A reduction of the number of stakes was accepted by producers in order to reduce the risks of new parasite contaminations. The development of mussel farming areas in the bay then stabilized with a total length of mussel bed lines of 272 kilometers (Figure 2).

Problems of biological contamination of the water led to classification of the productive Eastern portion of the bay as unhealthy for shellfish farming under current European legislation. A new (provisional) classification of the area East of Banc des Hermelles was adopted in 1997 that allowed shellfish farming if purified before being sold for consumption (Frangoudes 1999, Fontenelle 2000). This opened the possibility for a new extension of shellfish farming to the East of the bay.

The development of mussel farming in the Mont-Saint-Michel Bay has thus been strongly influenced by both water quality and trophic interactions. Variations in water quality in different points of the bay, mainly due to pollution carried by rivers and streams, have directly influenced which areas are open for the production of mussels. Competition for primary production between mussel farmers, and between mussel and oyster farmers, has also been determinant. This competition is strong in the Western part of the bay, where productivity is lowest and where oyster beds are close to mussel bed lines, and low in the Eastern part of the bay where productivity is highest. An additional constraint relates to predation of mussels 
by wild birds, which are present in the protected areas of the bay. It has recently been suggested that important losses of production in tonnage could be due to such predation (Bellanger 2002). This occurs with decreasing intensity from the Eastern part of the mussel growing zone to the Western part, with particularly high levels near the Banc des Hermelles, a protected area which serves as an important habitat for large colonies of black scoters (Melanitta nigra). Trophic interactions in the bay's ecosystem thus create two major constraints on mussel farming activity with an opposite west-east gradient. The spatial distribution of primary production causes stronger constraints in the Western part of the bay, while bird predation imposes stronger constraints in the Eastern part of the bay.

Many collective actions have been undertaken by farmers to regulate production capacity. An estate plan was established in 1957 that fixed the minimal spacing of mussel-bed lines and stakes (Frangoudes 1999, Fontenelle et al. 1998, Fontenelle 2000). In the early 1970s, following a new outbreak of Mytilicola intestinalis, farmers created a professional union that advocated a reduction in the density of stocks on mussel beds (Gasquet 1996, Fontenelle 2000). However, the density of stakes was still excessive in the 1980s (Gasquet 1996, Frangoudes 1999). A new agreement in 1985 resulted in thinning mussel beds but increased the overall area exploited for mussel farming. The ensuing reduction in biomass affected $76 \%$ of the mussel bed lines, and led to a $40 \%$ decrease of the number of stakes used (Figure 2). It was partly compensated by the creation of two new rows of mussel-bed lines to the North of the Saint-Benoît-des-Ondes and Cherrueix zones (Gasquet 1996, Frangoudes 1999, Fontenelle 2000). This led to significant improvements in the unit average productivity of mussel bed lines. Collective arrangements were also established by farmers concerning the allocation of newly opened zones. In particular an agreement was reached concerning the latest extension to the East of the bay between mussel and oyster farmers: mussel farmers were to transfer part of their mussel beds to the new production area, while oyster farmers, located in the Western part of the bay, would occupy the areas thus made available around Saint-Benoît-des-Ondes (Davaine 2002).

\section{Materials and methods}

The analysis of farmer responses to ecological constraints is based on the results of a survey of mussel farms, conducted in June 2002. The survey, based on direct interviews, focused on four sets of questions concerning: (1) the land structure of the farms; (2) production, costs and earnings; (3) impacts of ecological constraints on mussel farming; and (4) institutional context in which the activity develops. Specific attention was granted to the way in which farmers have adapted to these interactions, and to the role of the institutional context in allowing for, or assisting in such adaptation.

For practical reasons, mussel farmers were contacted in the big land-based farming centers of Le Vivier-sur-mer. No a priori sampling strategy was used, and all the farmers responding positively to the survey in these centers were interviewed. The quality of the sample of interviewed farmers was controlled ex-post, based on data available to describe the population of mussel farmers and their activity. This allowed an analysis of the sampling rate, according to the type of farms operating in the bay.

Overall, a fairly good coverage of the population was achieved in the survey. The sample covered $29 \%$ of all mussel farms in the bay and $38 \%$ of both the total length of mussel bed lines and the annual production of mussels (Table 1). This implies that large and mediumsized firms tended to be over-represented in the sample, compared to the smaller firms operating in the bay. This led to a degree of over-representation of companies with formal legal status and a high degree of mechanization, as compared to the small family-run farms. The sample included $40 \%$ of companies designated as exploitation societies, and $39 \%$ of companies using an amphibian ship. These machines were introduced in 1977 and enabled mussel growers to become less dependent on the tide (Verger and Le Vot 2002). The sample comprised similar proportions of exclusive mussel farmers $(28 \%)$ and of farms with 
mixed activities (mussel and oyster farming) (32\%). The sample contained a majority (5 out of 7) of mixed farms with predominant mussel farming activities. This could also explain the relatively high coverage of mussel bed lines in the sample, in comparison to the number of farms surveyed.

The percent of stakes represented in the sample for each geographic zone was used to assess the representativeness of the sample in terms of spatial heterogeneity zone (Table 2). The percentages of stakes included in the survey ranged from 34\% to $39 \%$, and were similar across the three zones. Data on investment costs, annual capital depreciation, variable production costs, and information on labor utilization were collected in the survey to assess the economic status of the farms surveyed. Based on the turnover generated by activities related to mussel farming (some farms collect earnings from resale of mussels or from resale of mussels or from services delivered to other mussel farms), the following economic performance indicators were calculated: 1) added value, defined as the turnover less intermediate consumption costs; 2) rate of added value, defined as the ratio of added value to turnover; 3) labor use, defined as the number of workers (including farm owner(s), permanent employees and seasonal workers) measured in terms of full-time equivalent; 4) rate of external employment, defined as the rate of full-time equivalent employees over the total full-time equivalent labor used (including family work); 5) apparent labor productivity, defined as the annual turnover obtained per full-time equivalent worker; 6) gross exploitation revenue (GR), defined as the added value less remuneration paid to workers, social security contributions and taxes (based on the assumption that the value of operator's labor was equal to the average value of a full-time equivalent employee as measured by the survey in each farm category); 7) provisions for capital depreciation, worked out according to two methods (linear depreciation approach, and depreciation proportional to the reverse order of years); 8) interest payments on total capital costs, based on an annual rate of $11 \%$ of the total capital invested that corresponds to a 4\% credit rate over a 20-yr period; 9) net profit (NP), defined as GR less interest on capital and annual provisions for capital depreciation estimated by the proportional approach method; 10) ratio of net profit to turnover; and 11) net return on total capital, defined as the ratio of the net profit over total capital costs. Provisions for capital depreciation were estimated on the basis of the declared value of equipment only. Costs of land acquisition were not included assuming that, in the bay, land has an increasing value over time, and does not need to be replaced. Interest payments on total capital costs were estimated on the basis of the investment needed to cover both equipment and land acquisitions.

Survey results were used to establish a typology of farms with respect to their land structure and to characterize the economic status of each farm category. The determinants of each farm category's location choices for mussel farming were then analyzed, taking into account the economic implications of distance to port, natural productivity differentials, and predation.

\section{Results}

\subsection{Typology of mussel farms according to their location choices}

The farms surveyed were ranked by increasing length of mussel bed lines owned in the central zone of Cherrueix because this was the most productive zone in the initial period of expansion of mussel farming. Three distinct categories of farm were characterized by varying degrees of geographic dispersion of production zones (Table 3, Figure 3): 1) Category 1. Farms with no mussel bed lines in the Cherrueix zone, and production structures exclusively located in the Saint-Benoît-des-Ondes and the Hermelles zones; 2) Category 2. Farms with production structures equally distributed among the three zones; and 3) Category 3 . Farms with production structures almost exclusively located in the central zone of Cherrueix. Seven 
farms were surveyed per category. Figure 3 presents the distribution of mussel bed lines in length among the three production zones according to the category of farm considered.

Location strategies were associated with markedly different sizes of farms (Figure 4). With an average length of mussel bed lines of 8,000 meters, Category 3 farms had the largest production capacity but there were no differences between Categories 1 and 2 in terms of size. Average annual production of Category 3 farms is 270 tons per year, as compared to the 130 tons average annual production of Category 2 and 3 farms.

Table 4 presents the economic profile of each farm category. Category 1 farms present medium levels of turnover and the lowest rate of added value of the three categories, with a low level of employment and medium levels of both labor productivity and provisions for capital depreciation. These characteristics lead to intermediate levels of gross exploitation revenue (GR) and net profit (NP). These farms have invested in new equipment in recent years, but have few employees, with most labor being supplied by family members.

Category 2 farms present slightly lower levels of turnover than those of Category 1 , but a much higher rate of added value, and a medium level of employment. They also present lower levels of investment in equipment but similar levels of interest paid on total capital costs. These characteristics lead to the lowest levels of labor productivity, GR, and NP observed in the sample, but the highest levels of return on total capital of the three farm categories. With an intermediate rate of external employment, a low level of equipment costs, and a total investment level similar to Category 1 farms, Category 2 farms appear to use less capital intensive production techniques and derive greater profits from high levels of investment in land.

Category 3 farms exhibit the largest production capacity. Investment costs (primarily land), levels of turnover, employment and added value are much higher than those of Category 1 and 2 farms. While Category 3 farms have the highest levels of GR and NP, labor productivity is equivalent to that of Category 1 farms. Profitability is similar to that of the two other farm categories due to a more capital intensive production structure.

\subsection{Determinants of location choices}

\section{Distance to port}

Land-based facilities are concentrated in Le Vivier-sur-mer at the same distance from the production zones of Saint-Benoît-des-Ondes and of Cherrueix, to protect natural habitat and the landscape. Figure 5 presents the average oil and fuel costs per ton of mussel produced, for the three categories of farms. The lowest unit costs of travel are observed for Category 3 farms which concentrate their activity in the central zone of Cherrueix. The highest unit costs of travel are observed for Category 1 farms which exploit mussel beds at the two ends of the bay. Category 2 farms, which exploit mussel beds in the three production zones, have intermediate unit costs of travel. This is probably due to the fact that the dispersion of mussel beds is partially compensated for by the continuity of farming locations, that provides some economies in travel costs. For Category 3 farms, the strategy of concentrating activity in only one zone thus allows a significant reduction in unit travel costs.

\section{Natural productivity differential}

The average productivity of each category of farm was calculated from the data regarding global production and the number of stakes exploited by the farm. While rapidly rising productivity gains were observed during the period of mussel farming development in the bay, the later periods of "transfers", "thinning", and standardization of farming practices were marked by a stabilization of the average productivity of mussel beds. It can thus be assumed that current productivity levels are a convenient proxy for the natural productivity of the exploited areas. Figure 6 presents the estimated productivity of the three categories of farm, expressed in kilograms per stake. The highest median productivity is observed for Category 1 and 2 farms, which hold between half and a third of their mussel-beds in the most 
productive Eastern zone of the Hermelles. In contrast, Category 3 farms, holding almost no mussel-beds in this zone, have the lowest median productivity. The data however show a higher degree of variability in the productivity of Category 2 farms, which display the most dispersed production patterns in the bay.

\section{Economic losses due to predation}

The farmers interviewed were asked to provide an estimate of the annual losses of mussels in tonnage due to predation. Total losses due to predation in the bay were estimated at about $10 \%$ of the annual potential production in tonnage, approximately 1,000 tons a year. This global estimate was found to be consistent with the estimates derived from ecological and biological studies (Bellanger 2002).

The information collected via the survey was then used to build a "without-predation" scenario, and to estimate the economic impacts of predation for each farm category, in order to assess whether the economic implications of predation were different according to the location choices of farmers. The maximum potential production in tonnage, without predation, was calculated on the basis of individual declarations in the survey. Given the relatively limited contribution of mussel production from the Mont-Saint-Michel Bay to the French market for mussels (approximately 110,000 tons consumed in 2001 (Girard \& Mariojouls 2003)), fixed prices were assumed. Maximum turn-over was then derived from the maximum tonnage without predation.

Two estimates of production cost were calculated to bracket value the varying levels of economic losses due to predation. In the first estimate, production costs remain the same even though the farm would be processing a larger tonnage of mussels without predation. This approach probably underestimates production costs and overestimates economic losses due to predation. In the second estimate, production costs vary in direct proportion to additional tonnage processed by farms. An increase in tonnage processed is assumed to entail a proportional increase in all costs, except those related to owners' remuneration, investment and interest payments. Because variable production costs can be expected to grow less than proportionally to turnover in practice, the figures obtained via this approach probably overestimate production costs in the absence of predation, which amounts to underestimating the economic losses due to predation.

Figure 7 presents the average results of this analysis by farm category for the year 2001. Losses due to predation are measured in terms of percentages of the estimated bracket value of key economic indicators in a without-predation scenario. Losses are estimated to be in the order of $10 \%$ of turnover for Category 1 farms, as compared to $8 \%$ for Category 2 farms and $6 \%$ for Category 3 farms. While the differences between farm categories increase slightly when losses are measured in terms of added value and gross exploitation revenue, they appear to be strongest when losses are considered in terms of net profit (32 to 37\% for Category 1 farms, 19 to $27 \%$ for Category 2 farms, and 14 to $19 \%$ for Category 3 farms). It thus appears that farms of Categories 2 and 3 are able to better contain the impacts of predation on the overall economic performance of their activity than Category 1 farms.

\section{Discussion}

\subsection{Location strategies}

The analysis above demonstrated that technical and ecological constraints on musselfarming in the Mont-Saint-Michel Bay have markedly differentiated effects on farms, according to their land structure. Category 1 farms are the most strongly affected by costs due to distance to port and to predation. This could be interpreted as the result of a lack of active location strategies. 
The land structures of the two other farm categories illustrate two adaptive responses aimed at taking best advantage of the heterogeneity of constraints in the bay. For Category 2 farms, exposure to predation was perceived as a fluctuating disadvantage. Farmers consider that predation does not always have the same level of negative impacts on harvesting. If predation is intense, economic losses recorded in the Hermelles zone will be compensated by the relative stability of production in the other zones, especially Cherrueix. If predation is low, farmers will strongly benefit from the much higher productivity of the Hermelles zone. Spatial diversification of their activity is thus fully justified, particularly if traveling costs can be economized. For Category 3 farms in the long run, the higher productivity of the Hermelles zone will not compensate for the negative impacts of predation and the higher traveling costs related to dispersed mussel beds. The strategy thus consists of limiting the risks by concentrating their activity in a zone of medium but relatively secure productivity in the Cherreix zone, which allows the lowest traveling costs. This strategy was followed by the farms that have made the largest investments in mussel farming, and which thus need to maintain fairly stable production levels.

\subsection{The role of institutional arrangements}

Local coordination initiatives have affected the evolution of the current pattern of mussel farming activities in the bay and the incentives for farmers of different farm categories to maintain or to change the location of their activity in the bay. For example, from the start of the expansion phase, the zone of Saint-Benoît-des-Ondes was recognized as the least productive zone in the bay, and the holders of concessions in this zone were given priority access to the new concessions by the administration when the Hermelles zone was created. This decision resulted from a collective agreement between the administration and the farmers and between farmers; priority access to the new concessions was given as compensation to farmers operating in the least productive area of the bay. This allocation rule largely explains the land structure of Category 1 farms, whose concessions are nearly equally distributed among these two zones. Owners of these farms apparently remained relatively passive in response to the technical and ecological constraints described above, simply benefiting from the negotiated allocation criteria. This behavior is also consistent with the fact that Category 1 includes all the mixed-activity farms deriving most of their earnings from oyster farming that takes place in the Western part of the bay.

In addition to these negotiated arrangements, the national regime for shellfish concessions has evolved toward a quasi-market system (Orfila 1990, Miner 1991, Bailly 1994), allowing active location choices. Using this quasi-market system, the larger farms of Category 3 established their activity preferentially in the Cherrueix area, which was the most productive area until the opening of the Hermelles zone to production, and the smaller farms of Category 2 distributed their activity in a balanced manner between the three production zones. The purchasing of concessions was thus mainly carried out by the larger farms (Category 3) pursuing a concentration objective, and by those farms that sought a geographic diversification of their activities (mainly those of Category 2).

Figure 8 presents the proportion of total length of mussel-bed lines in each production zone, whose property changed hands during the years 1989-2001. It shows that the proportion of "bouchots" (rows of stakes) exchanged each year can be significant. It also shows the high inter-annual and inter-zone variability of concession exchanges. The variations observed can be at least partly related to the administrative decisions regarding the expansion of production areas in the bay, and to the allocation criteria decided locally for granting access to the new areas. For example, the opening for production in 2002 of the formerly contaminated zone was being discussed by producers during the late nineties, and an agreement was achieved in 1999 regarding the allocation of access to the new zone. This agreement stated that all the concessions located in the Saint-Benoît-des-Ondes zone should be relocated in the new zone (Fontenelle 2000). Not surprisingly, nearly $9 \%$ of the bouchots of this poorly productive zone were purchased that same year. Similar speculations probably explain at least in part the high level of exchanges observed in 1991 and 1995. 
The price of concessions also appears to be highly variable in time and space (Figure 9). In particular, the period of negotiation regarding the re-allocation of production zones, which started in the mid nineties, is marked by a wide and fluctuating difference in average prices observed in each zone. When the new zone was finally opened in 2002 , however, prices for concessions in the different zones became fairly similar again. These evolutions can probably be related to farmer expectations in relation to the locally negotiated rules for expanding and controlling mussel production.

\section{Conclusion}

The spatial distribution of a mussel farm's production zones is a key element in its capacity to adapt to technical and ecological constraints in Mont-Saint-Michel Bay. There is strong evidence that, in addition to local coordination initiatives, private exchanges in concessions are largely used by farmers as an adaptive mechanism.

The combination of locally defined allocation rules and concession exchanges has led to well differentiated land structures observed for the three farm categories. The underlying choices made by farmers can be explained by economic considerations related to selecting preferred locations and in diversifying the location of their concessions. Mussel farmers sought to optimize both their short-term exploitation results and the value of their land patrimony. While location choices in the short-run can have consequences on the global productivity level of farms, in the long-run these choices also have consequences in terms of the total value of a farm's assets, including the value of concessions. Such a value is bound to reflect the various attributes of concessions with respect to mussel farming, in particular, as regards the ecological and technical constraints imposed on this activity.

It is noteworthy that under such a regime for the regulation of access to shellfish farming "land", decisions taken by the administration regarding the expansion of production areas and the criteria for allocating access to the new concessions can have significant consequences on the quasi-market for concessions, and on the value of concessions. As would be expected from any market-based system designed to regulate access to a natural resource, the announcement of an allocation rule based on existing ownership of concessions can spur demand for certain concessions, which in turn may influence the prices paid for these concessions. This increased demand may result from either attempts to gain the rights needed to access the new more productive zone, speculative behavior, or both. Due to eviction effects, the increased demand may have consequences opposite to those expected in terms of who gains access to the new zone. From a policy perspective, the role of administrative intervention in the overall regulation of mussel farming in the bay should thus be considered as a key determinant of the dynamics of concession exchanges, and of the ensuing ability for producers to adapt to ecological constraints.

\section{Acknowledgments}

This work was carried out as part of the Mont-Saint-Michel Bay research project, funded under the French National Program on the Coastal Environment. The authors acknowledge the support received from the program to carry out this research, and wish to thank the members of the coastal laboratory of Saint-Malo (Ifremer), and the persons from the profession and the administration who accepted to participate in the survey. The authors also wish to thank two anonymous reviewers for their helpful comments on a previous version of this article. 


\section{References}

Aarset, B. (1998) Norwegian salmon-farming in transition: dislocation of decision control. Ocean and Coastal Management, 38, 187-206.

Asche, F., Guttormsen, A.G. \& Tveterås, R. (1999) Environmental problems, productivity and innovations in Norwegian salmon aquaculture. Aquaculture Economics and Management, 3, 19-29.

Bailly, D. (1994) Economie des ressources naturelles renouvelables : la gestion des bassins conchylicoles. Ph.D. thesis, University of Rennes. (In French).

Bailly, D. \& Paquotte, P. (1996) Environment and aquaculture development. Coastal Management, 24, 251-269.

Bellanger, X. (2002) La macreuse noire (Melanitta nigra) en baie du Mont-Saint-Michel : bilan des connaissances et analyse de l'impact sur la mytiliculture. Master's thesis, Institute of Applied Ecology, Angers. (In French).

Berg, H. (2002) Rice monoculture and integrated rice-fish farming in the Mekong Delta, Vietnam - economic and ecological considerations. Ecological Economics, 41, 95-107.

Davaine, A. (2002) La mytiliculture en baie du Mont-Saint-Michel : analyse économique du secteur et de ses interactions avec le milieu, les autres secteurs d'activité et l'environnement institutionnel. Master's thesis, Mediterranean University, Marseille. (In French).

Fontenelle, G. (2000) Dynamiques de cogestion : un problème, plusieurs solutions ; cas de la baie du Mont-Saint-Michel, France. Revue de l'Université de Moncton, hors série, 19-45. (In French).

Fontenelle, G., Bailly, D., Le Mao, P. \& Gerla, D. (1998) How and why blue mussel growers succeeded in developing a long term co-management process to use marine open access resources. Paper presented at the $\mathrm{VII}^{\text {th }}$ Annual Conference of the International Association for the Study of Common Property, " Crossing boundaries ", Vancouver, June 1998.

Frangoudes, K. (1999) L'occupation du Domaine Public Maritime par des cultures marines: le cas de la Baie du Mont-Saint-Michel. Coastman Working Papers 11, Rennes. (In French). Gasquet, R. (1996) Historique et évolution de la conchyliculture dans la baie du Mont-SaintMichel. Master's thesis, INA-PG, Paris. (In French).

Girard, S. \& Mariojouls, C. (2003) French consumption of oysters and mussels analysed within the European market. Aquaculture Economics \& Management, 7, 319-333.

Goulletquer, P. \& Le Moine, O. (2002) Shellfish farming and coastal zone management development in the Marennes-Oléron Bay and Charentais Sounds (Charente Maritime, France): a review of recent developments. Aquaculture International, 10, 507-525.

Guillotreau, P. \& Cunningham, S. (1994) The Management Implications of Overlapping Property Rights: the Case of the Solent Oyster. CEMARE Fishery Research Paper 71, Portsmouth.

Hishamunda, N. \& Ridler, N.B. (2003) Sustainable commercial aquaculture: a survey of administrative procedures and legal frameworks. Aquaculture Economics and Management, 7, 167-178.

Howlett, M. \& Rayner, J. (2004) "(Not so) smart regulation"? Canadian shellfish aquaculture policy and the evolution of instrument choice for industrial development. Marine Policy, 28, 171-184.

Le Mao, P. \& Gerla, D. (1998) La conchyliculture en baie du Mont-Saint-Michel. Bulletin Trimestriel de la Société pour l'Étude et la Protection de la Nature en Bretagne, 169, 28-37. (In French).

Lefeuvre, J.-C., Bouchard, V., Feunteun, E., Grare, S., Laffaille, P. \& Radureau, A. (2000) European salt marshes diversity and functioning: the case of the Mont-Saint-Michel bay, France. Wetlands Ecology and Management, 8, 147-161.

Marshall, J. (2001) Landlords, leaseholders \& sweat equity: changing property regimes in aquaculture. Marine Policy, 25, 335-352. 
Miner, M.-C. (1991) L'aquaculture : le régime juridique de l'exploitation aquacole. In Le droit du littoral et de la mer côtière (dir. J.-M. Becet \& D. Le Morvan), pp 300-312. Economica, Paris. (In French).

Mongruel, R. (2002) Concilier activités humaines et valorisation du patrimoine naturel en baie du Mont-Saint-Michel : apports de l'analyse économique (Economic issues regarding ecosystems management in the Mont-Saint-Michel bay: an analysis framework proposal). Océanis, 28, 151-173. (In French).

Muir, J.F., Brugere, C., Young, J.A. \& Stewart, J.A. (1999) The solution to pollution? The value and limitations of environmental economics in guiding aquaculture development. Aquaculture Economics and Management, 3, 43-57.

Nickerson, D.J. (1999) Trade-offs of mangrove area development in the Philippines. Ecological Economics, 28, 279-298.

Orfila, G. (1990) Droit de la conchyliculture et de l'aquaculture marine. Éditions Bordessoules, Saint-Jean-d'Angely. (In French).

Pérez Agúndez, J.A \& Kalaydjian, R. (2003) Specialisation based coastal zone management: the case of a mussel farming zone on the French Mediterranean. Paper presented at the $\mathrm{XV}^{\text {th }}$ Annual EAFE Conference, Brest, 14-16 May 2003.

Primavera, J.H. (2000) Development and conservation of Philippine mangroves: institutional issues. Ecological Economics, 35, 91-106.

Tisdell, C. (1999) Overview of environmental and sustainability issues in aquaculture. Aquaculture Economics and Management, 3, 1-5.

Verger, F. \& Le Vot, M. (2002). The developments in the bay. In: The Bay of Mont-SaintMichel and the Rance Estuary: Recent Development and Evolution of Depositional Environments (eds C. Bonnot-Courtois, B. Caline, A. L'Homer \& M. Le Vot), pp 99-108. Bull. Centre Rech. Elf Explor. Prod., Mém. 26, Pau.

Wind, H.G. \& de Kok, J.-L. (2002) Interdisciplinary modelling: gaps and bridges. Marine Policy, 26, 243-251. 


\section{Figures}

Figure 1 - Location of shellfish farming in Mont-Saint-Michel bay in 2002.

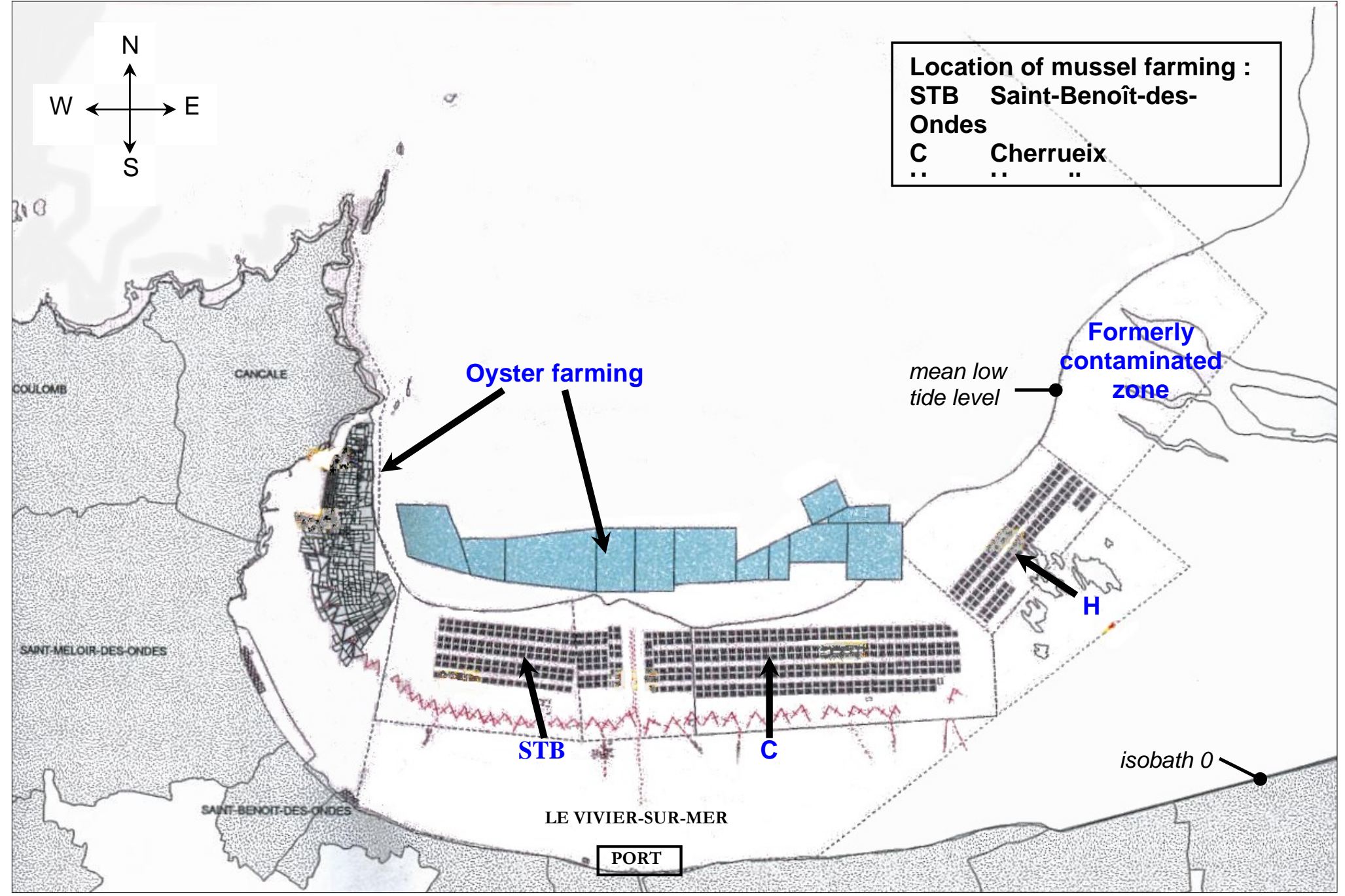


Figure 2 - Development of mussel farming in Mont-Saint-Michel bay, 1954-1994.

tons ; grams/stake

meters ; numbers

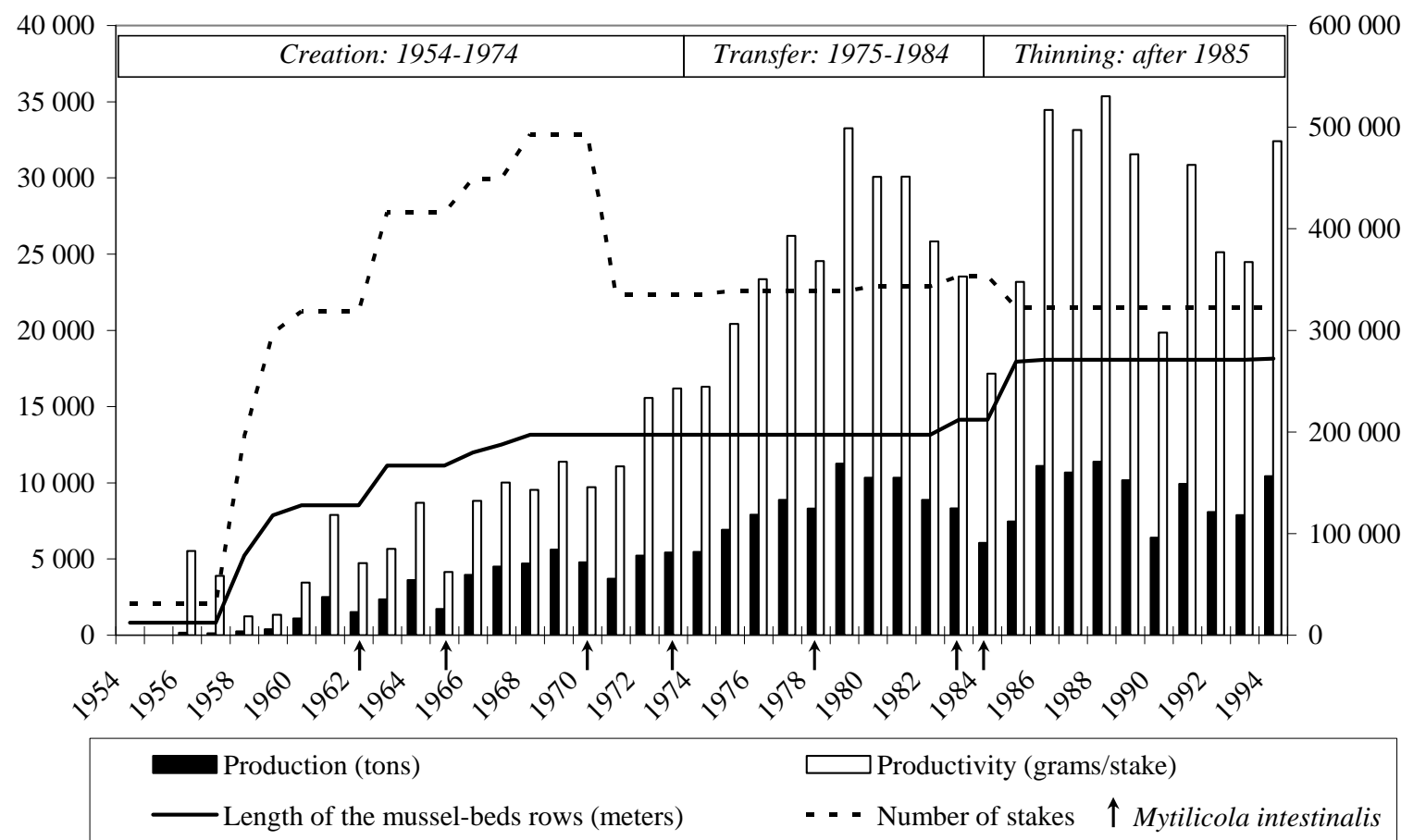

Source: from Gasquet, 1996 and Fontenelle, 2000.

Figure 3 - Spatial allocation of mussel bed lines per zone, for each farm category in 2001 (box and whisker plot in meters)

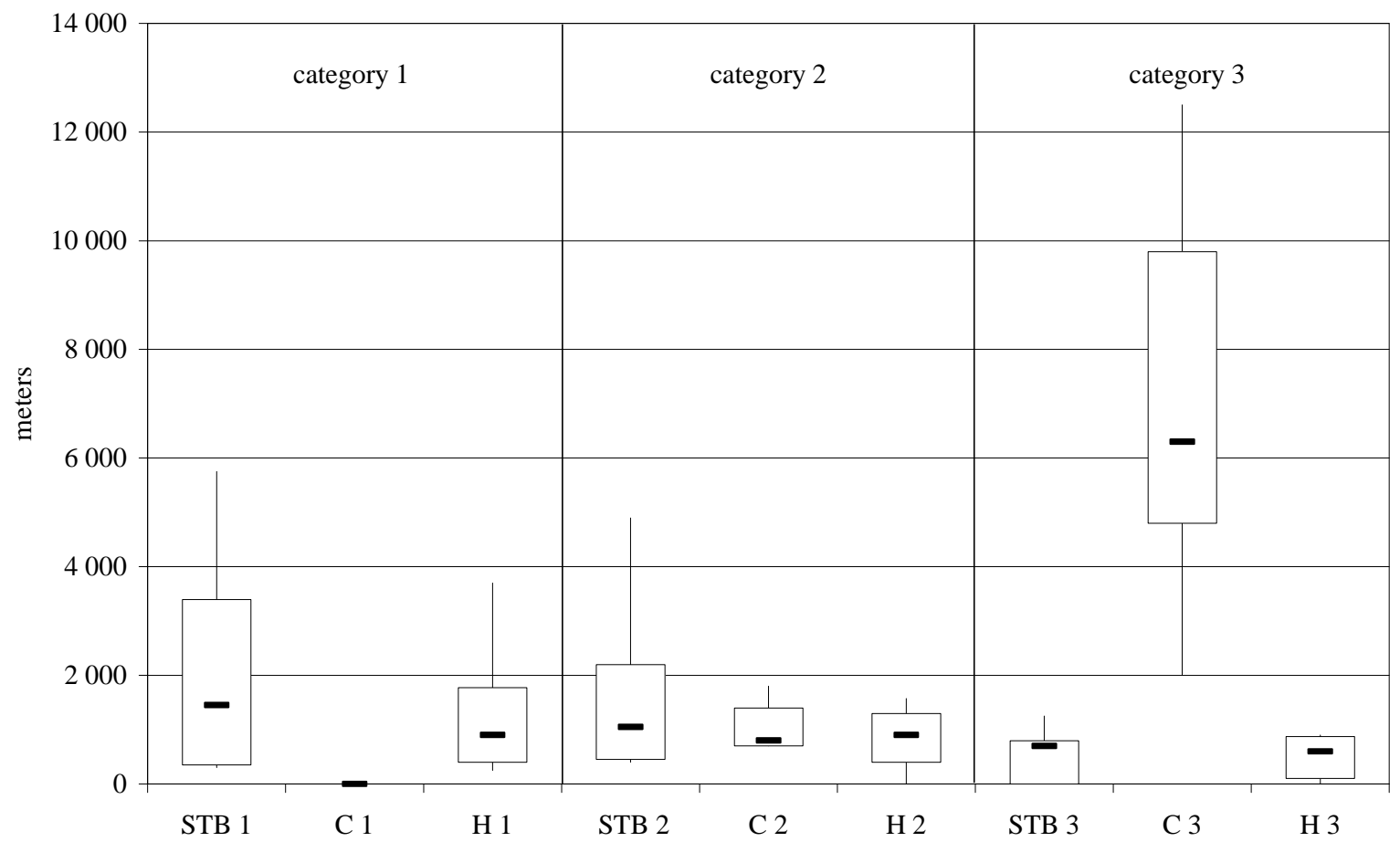


Figure 4 - Total lengths of mussel bed lines, per farm category in 2001 (box and whisker plot in meters)

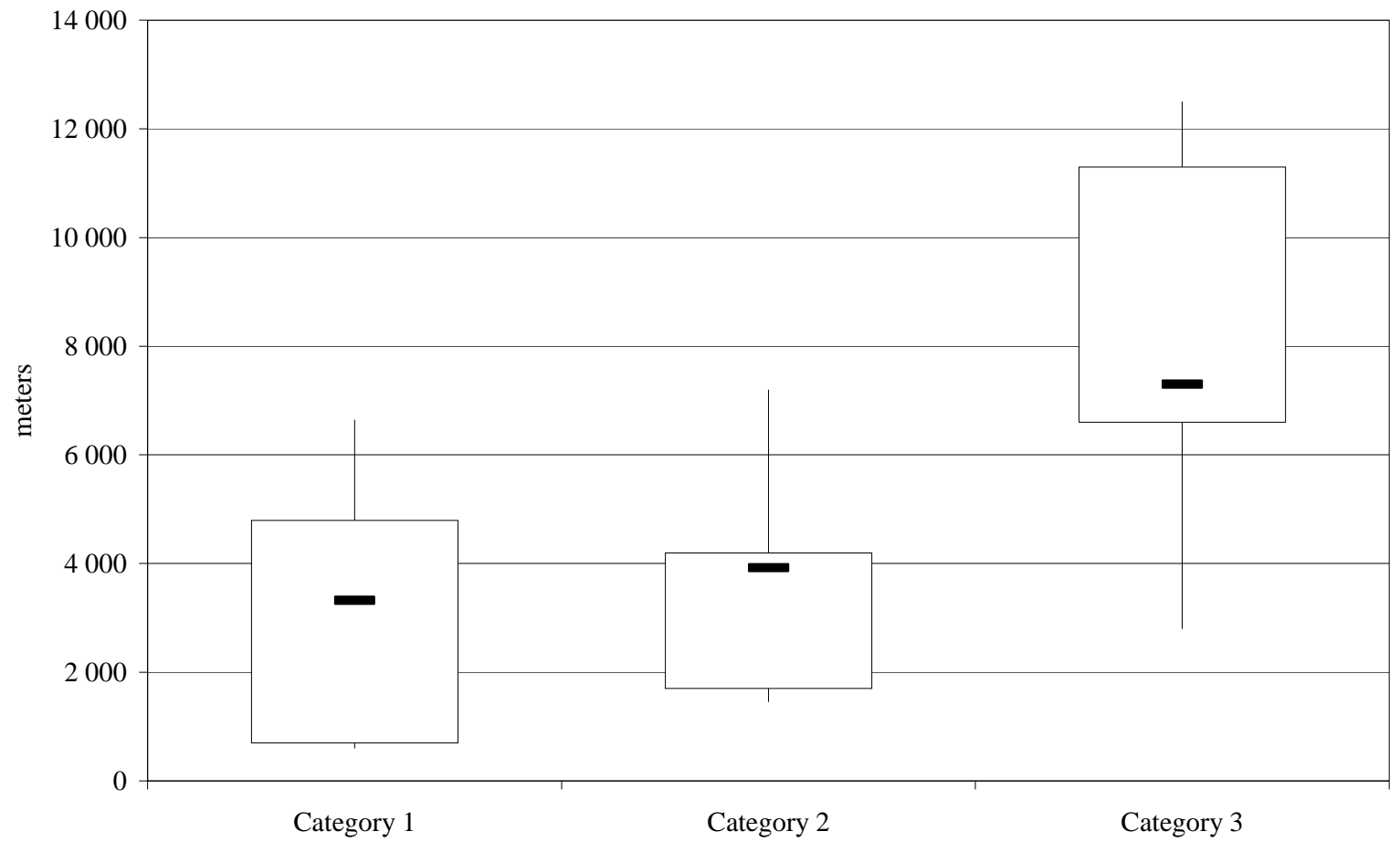

Figure 5 - Fuel and oil average costs per ton of mussels produced, per farm category in 2001 (box and whisker plot in Euro/ton)

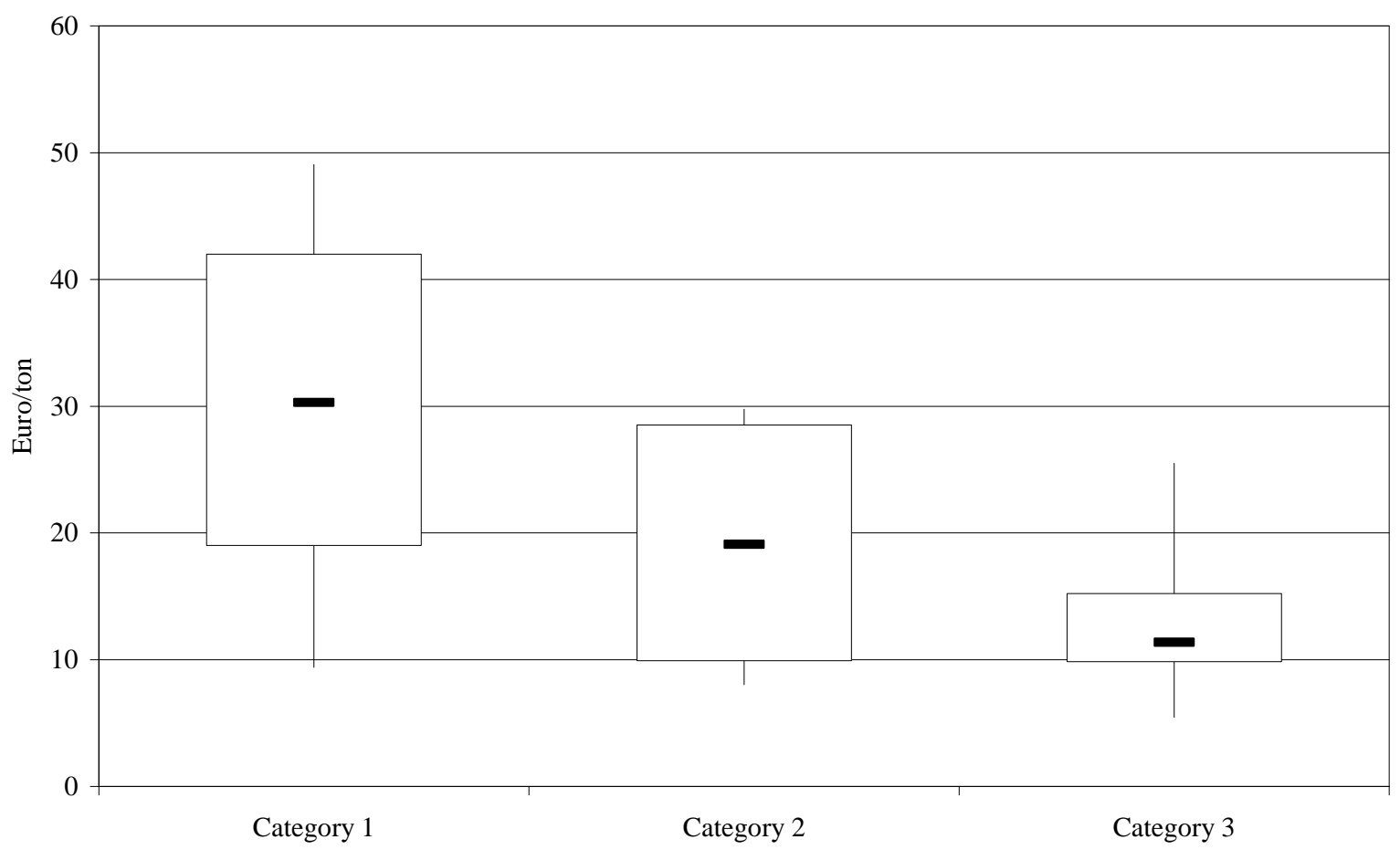


Figure 6 - Average productivity per farm category in 2001 (box and whisker plot in kg/stake)

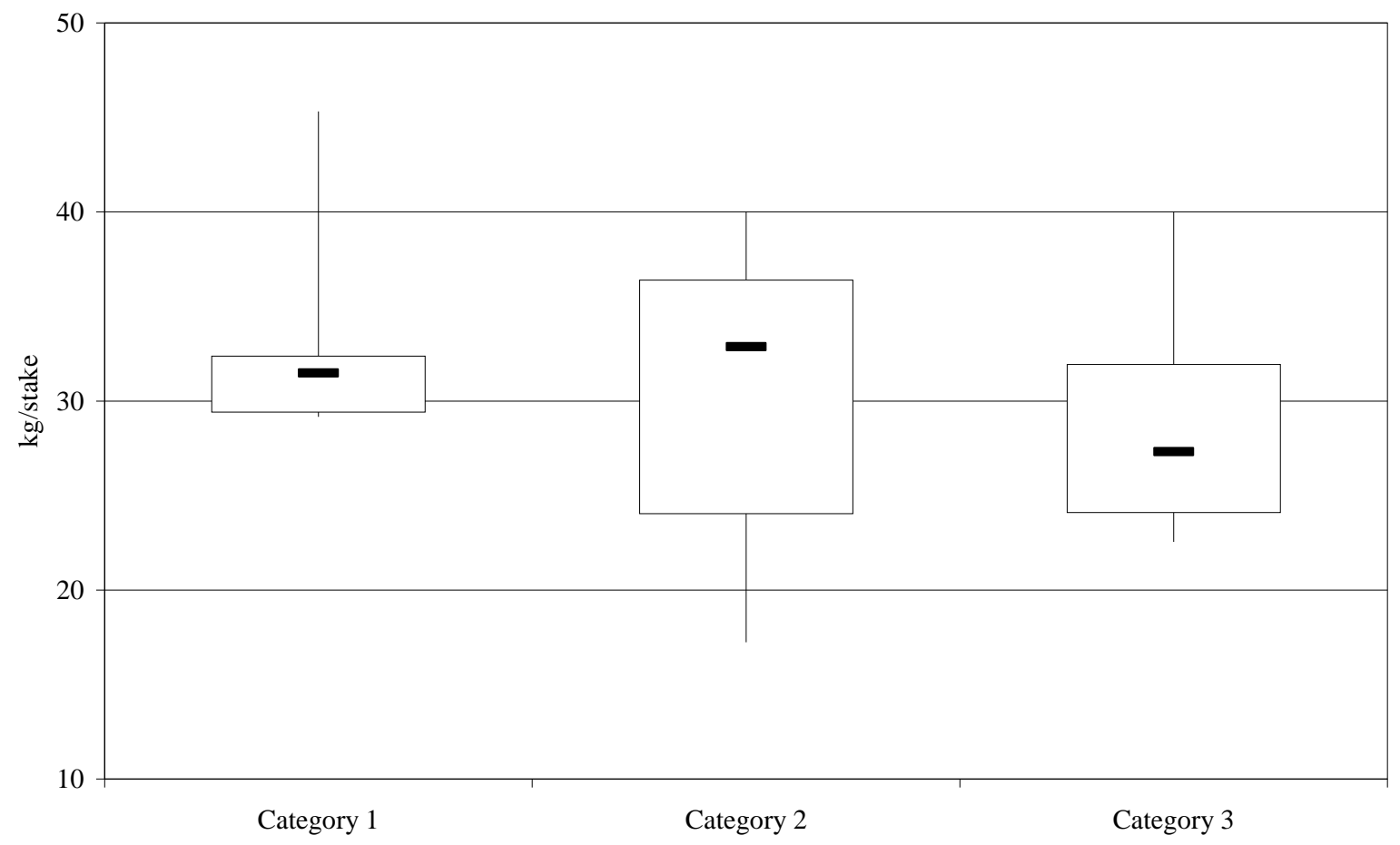

Figure 7 - Observed value of key economic indicators (Euro), and minimum and maximum estimates of the losses due to predation (\% of without-predation value)

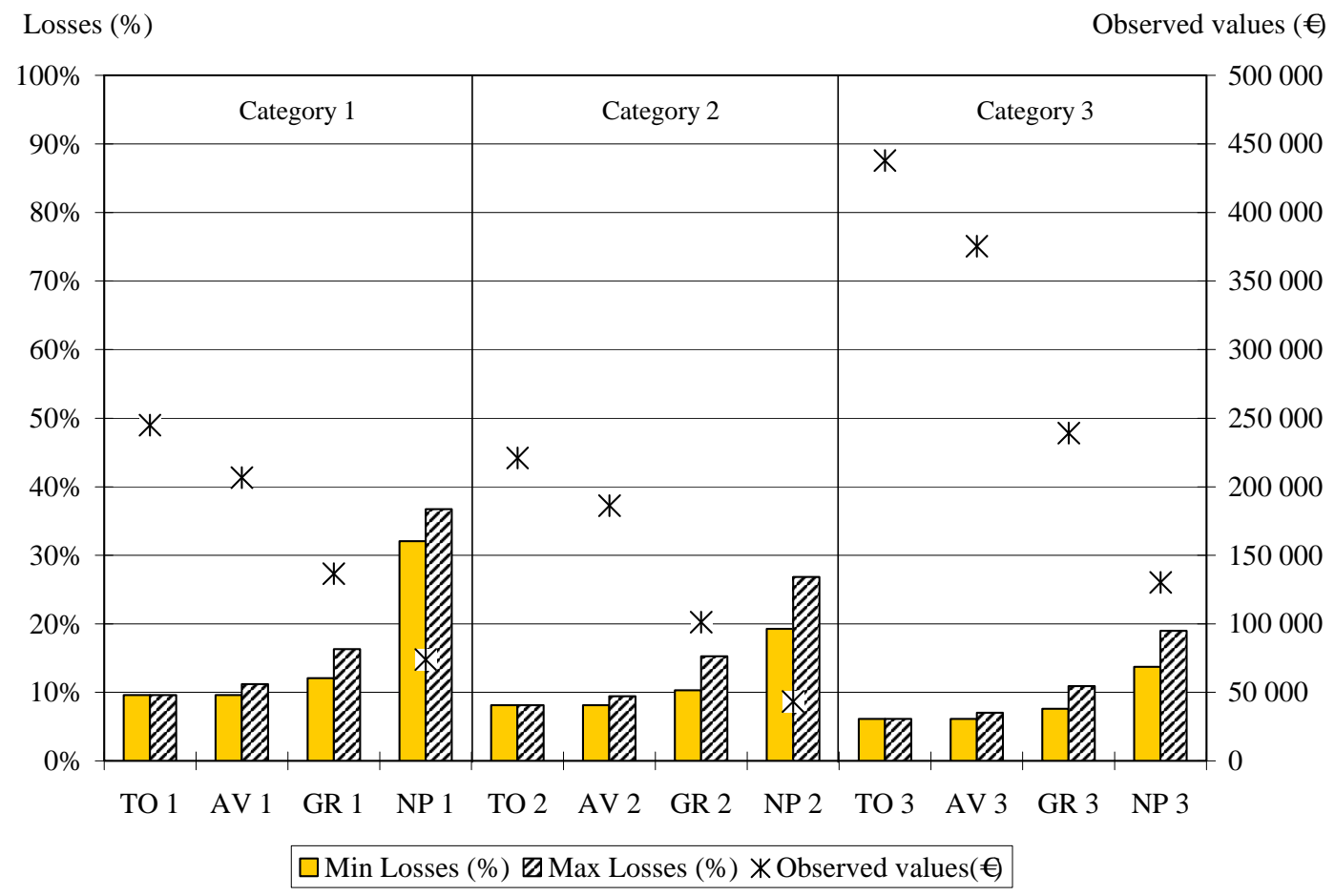

TO: turnover, AV: added value, GR: gross exploitation revenue, NP: net profit with proportional depreciation of capital. Stars mark the value of each indicator observed during the year 2001.

Figure 8 - Rate of exchanged concessions per production zone* 


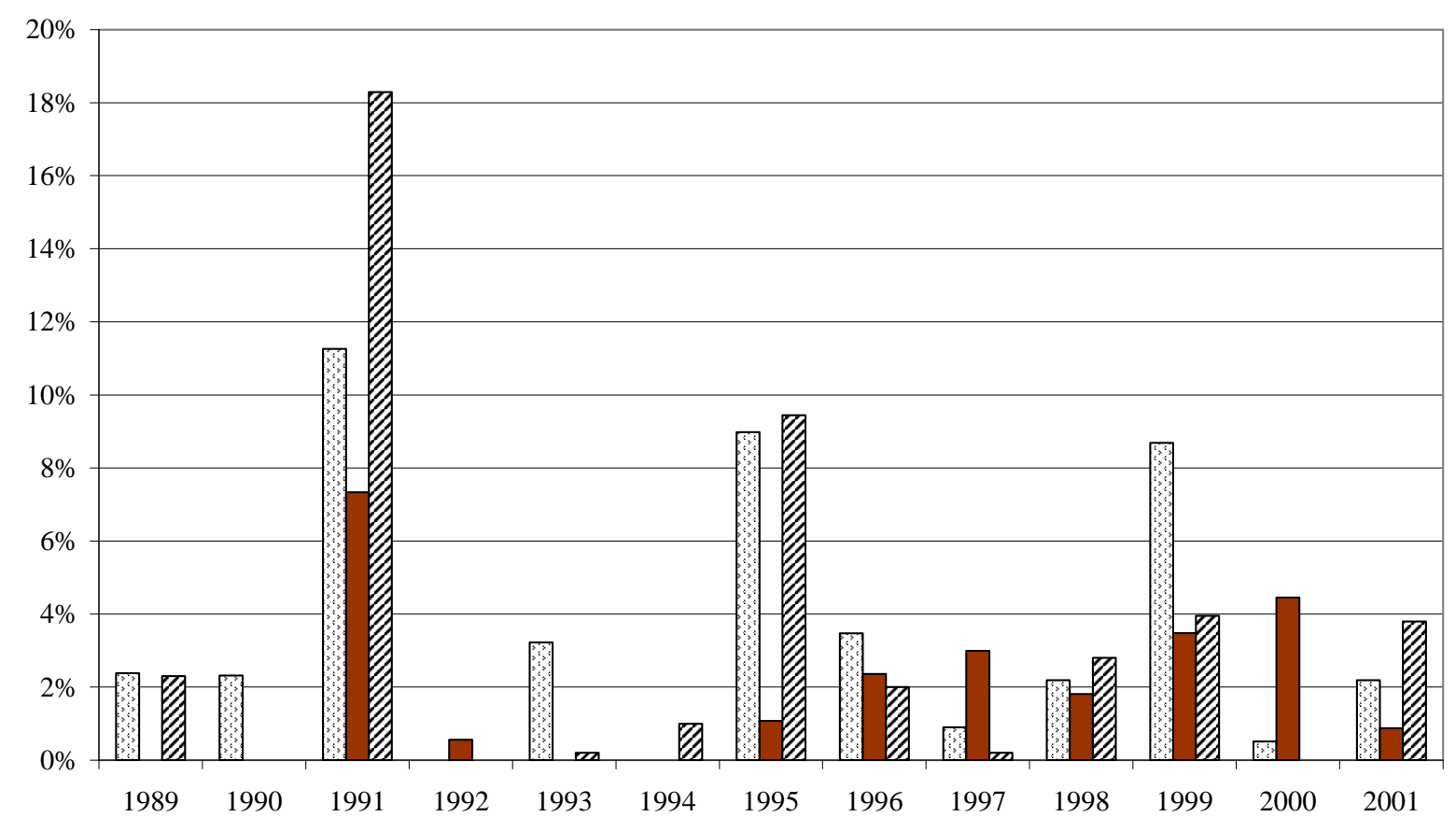

国 Saint-Benoît-des-Ondes $\square$ Cherrueix $\square$ Hermelles

* Evolution of the percentage of existing mussel-bed lines exchanged either within or outside the family of mussel-farmers.

Figure 9 - Average exchange value of the concessions per production zone*

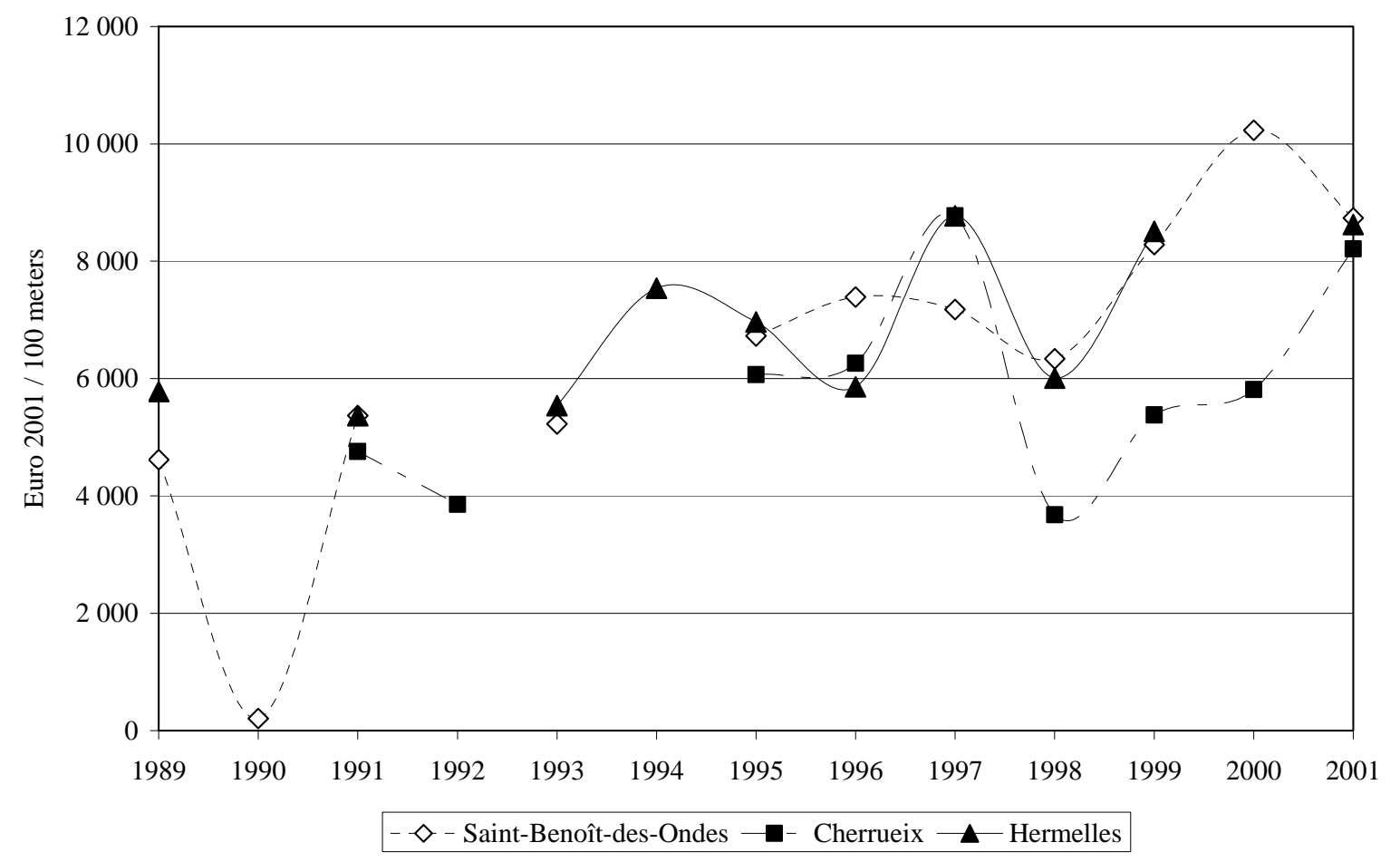

* This estimate is based on the declared prices of the sold concessions, as recorded by the Administration. 
Table 1 - Representativeness of the surveyed sample of mussel farming companies

\begin{tabular}{lrrr} 
& Population & Sample & $\%$ S/P \\
\hline Number of mussel farms & 73 & 21 & $28,8 \%$ \\
incl. mussel breeding only & 51 & 14 & $27,5 \%$ \\
incl. mussel and oyster & 22 & 7 & $31,8 \%$ \\
'Estab̆lishments approved for the & 69 & 20 & $29,0 \%$ \\
Length of the mussel beds lines & 272,10 & 103,35 & $38,0 \%$ \\
Annual production of mussels & 10000 & 3757 & $37,6 \%$ \\
Exploitation societies & 45 & 18 & $40,0 \%$ \\
Producers cooperatives & 2 & - & - \\
Enterprises using amphibian & 49 & 19 & $38,8 \%$ \\
\hline
\end{tabular}

Table 2 - Representativeness of the sample in terms of geographic coverage of the three mussel production zones

\begin{tabular}{lrcc}
\hline & Population & Survey & \% S/P \\
\hline Total number of mussel-breeding stakes & 322010 & 12164 & $37,8 \%$ \\
Number of stakes in the St-Benoît-des- & 85470 & 32450 & $38,0 \%$ \\
Number of stakes in the Cherrueix area & 158180 & 62260 & $39,4 \%$ \\
Number of stakes in the Hermelles area & 78360 & 26930 & $34,4 \%$ \\
\hline
\end{tabular}

Table 3 - Typology of mussel farms of the Mont-Saint-Michel bay according to the geographic distribution of their concessions (\% of mussel-bed lines per zone)

\begin{tabular}{|c|c|c|c|c|c|c|}
\hline & \multicolumn{2}{|c|}{ Category 1} & \multicolumn{2}{|c|}{ Category 2} & \multicolumn{2}{|c|}{ Category 3} \\
\hline $\begin{array}{l}\% \text { of mussel- } \\
\text { bed lines per }\end{array}$ & $\begin{array}{l}\text { Averag } \\
\text { e }\end{array}$ & $\begin{array}{l}\text { Standard } \\
\text { deviation }\end{array}$ & $\begin{array}{l}\text { Averag } \\
\text { e }\end{array}$ & $\begin{array}{l}\text { Standard } \\
\text { deviation }\end{array}$ & $\begin{array}{l}\text { Averag } \\
\text { e }\end{array}$ & $\begin{array}{l}\text { Standard } \\
\text { deviation }\end{array}$ \\
\hline STB & $57,9 \%$ & $22,1 \%$ & $40,9 \%$ & $15,9 \%$ & $9,6 \%$ & $9,2 \%$ \\
\hline C & $0 \%$ & $0 \%$ & $35,4 \%$ & $18,6 \%$ & $84,0 \%$ & $11,4 \%$ \\
\hline H & $42,1 \%$ & $22,1 \%$ & $23,7 \%$ & $14,2 \%$ & $6,4 \%$ & $4,1 \%$ \\
\hline
\end{tabular}

STB: Saint-Benoît-des-Ondes; C: Cherrueix; H: Hermelles. 
Table 4 - Economic indicators 2001 per farm category

\begin{tabular}{|c|c|c|c|c|c|c|}
\hline \multirow{2}{*}{ Economic indicators } & \multicolumn{2}{|c|}{ Category 1} & \multicolumn{2}{|c|}{ Category 2} & \multicolumn{2}{|c|}{ Category 3} \\
\hline & Average & $\begin{array}{l}\text { Standard } \\
\text { deviation }\end{array}$ & Average & $\begin{array}{l}\text { Standard } \\
\text { deviation }\end{array}$ & Average & $\begin{array}{l}\text { Standard } \\
\text { deviation }\end{array}$ \\
\hline Turn Over (Euro) & 244901 & 164885 & 220872 & 120534 & 437912 & 245474 \\
\hline Added Value (Euro) & 206680 & 143515 & 186158 & 110522 & 375417 & 214105 \\
\hline Rate of Added Value (\%) & $80,1 \%$ & $13,6 \%$ & $81,6 \%$ & $7,7 \%$ & $85,3 \%$ & $2,2 \%$ \\
\hline Total Workers (full-time equivalent) & 2,62 & 1,40 & 3,20 & 1,22 & 5,14 & 1,97 \\
\hline including enterprise owners & 1,29 & 0,49 & 1,57 & 0,45 & 2,14 & 0,69 \\
\hline including employees & 1,33 & 1,25 & 1,63 & 1,07 & 3,00 & 1,71 \\
\hline External employment rate (\%) & $39,8 \%$ & $27,9 \%$ & $45,4 \%$ & $23,1 \%$ & $55,7 \%$ & $14,6 \%$ \\
\hline $\begin{array}{l}\text { Apparent labour productivity } \\
\text { (Euro/full time worker) }\end{array}$ & 86882 & 36625 & 64289 & 20191 & 82596 & 21626 \\
\hline Gross Exploitation Revenue (Euro) & 136634 & 98142 & 101191 & 66153 & 239039 & 181626 \\
\hline $\begin{array}{l}\text { Provisions for capital depreciation, } \\
\text { linear depreciation approach (Euro) }\end{array}$ & 16271 & 8411 & 13881 & 8443 & 23633 & 13286 \\
\hline $\begin{array}{l}\text { Provisions for capital depreciation, } \\
\text { proportional depreciation (Euro) }\end{array}$ & 20159 & 11955 & 16467 & 11610 & 30512 & 16572 \\
\hline Interests on capital (Euro) & 42631 & 20222 & 41525 & 25961 & 78366 & 34071 \\
\hline Net Profit (Euro) & 73843 & 82578 & 43199 & 39544 & 130161 & 136008 \\
\hline Net Profit to Turn Over (\%) & $15,4 \%$ & $29,5 \%$ & $19,8 \%$ & $18,9 \%$ & $24,6 \%$ & $11,6 \%$ \\
\hline Return on Capital (\%) & $14,9 \%$ & $22,8 \%$ & $16,3 \%$ & $15,9 \%$ & $15,5 \%$ & $9,5 \%$ \\
\hline
\end{tabular}

